\title{
Peertechz
}

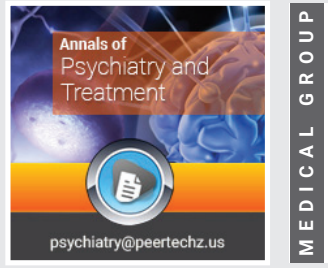

\section{Promoting ethnic relations in the current Ethiopia}

\section{Shemsedin Ziyad Mohamed*}

MA, Psychology, Haramaya University, Ethiopia
Received: 27 October, 2021

Accepted: 05 December, 2021

Published: 09 December, 2021

*Corresponding author: Shemsedin Ziyad, MA Psychology, Haramaya University, Ethiopia, Tel: +251912996530; E-mail: fitadost@gmail.com

ORCID: https://orcid.org/0000-0001-8651-4376

Keywords: Ethnic relation; Stereotypes; Prejudice and Ethnocentrism

Copyright: @ 2021 Mohamed SZ. This is an openaccess article distributed under the terms of the Creative Commons Attribution License, which permits unrestricted use, distribution, and reproduction in any medium, provided the original author and source are credited.

https://www.peertechzpublications.com

\section{Check for updates}

\begin{abstract}
One of the greatest challenges of Ethiopia is to promote wider societal development because the notions of ethnicity are fall prey to atomized competitions, hostility, or conflicts. These fraudulent competitions are directed in the struggle for political power, public offices, and socioeconomic opportunities by mobilizing their constituencies to think except 'their own members' are in power, they are unable to secure the national benefits. Nevertheless, ethnicity does neither inherently revolutionary nor impermeable, as many multi-ethnic nations do not have major troubles with their diversities but are a potential factor for cultivation. Understanding the psychological perspective that improves ethnic group relations of the family can assist notify involvements to enhance ethnic group members of the family. This seminar examines social psychological manners of ethnic perception and relation which are fundamental to promote ethnic members of the family and discusses how those forces may be forwarded to enhance ethnic organization members of the family, regularly through the enchaining of high-quality ethnic organization contact. I similarly keep in mind how promoting ethnic relationships advantaged and deprived corporations may also reply differently at the manner to involvements, and how a focal point frequently on improving high-quality ethnic group attitudes may also fall brief of ameliorating structural inequality among societies. I pick out modern conceptual and realistic demanding situations and advocate guidelines for the future. The result of the study shows that social psychology contributes undoubtedly to society via promoting social harmony, positive, cooperative relationships among contributors of various companies reduces tension and may generalize the significance of organization memberships, improves shared identities, and tremendously apprehending organization variations. Emphasized ethnic group relations at the local area by relating to Eastern Hararghe Zone of Amahara, Oromo, Somali, and other ethnics where living, cultures particularly, in Jarso Woreda is on the individual, which in its worst forms of ethnic relations can foster selfishness or indifference to others. However, promoting a sense of relations goes beyond a single ethnic group rather focus on interdependence and relationships.
\end{abstract}

\section{Introduction}

Nowadays, most of the world's countries are multiethnic, due to thousands of years of migration. Some nations have been political entities with more ethnic groups for very long periods. Some countries have recognized 'new citizens or lasting residents' from other countries, with diverse backgrounds in race, national origin, language, and religion. In some nations (such as today's western European countries), the unsettled who have settled down for decades or even generations have become a more or less essential part of the local people, even though the acquiring country may not have given them citizenship or 'permanent residency'. Based on a sociological point of view, every one of those social groups with the aforesaid features is viewed as a multi-ethnic society.
Ethiopia is one of the most multi (ethnic, cultural, and religious) nations in Africa as the result of the immigration of Afro-Asiatic super-language families. Unlike the other of Africa, our heterogeneousness [1] is not an unintended outcome of alien imposition. In whatever political units with a multiracial or multi-ethnic composition, the political body, and elite group are confronted with such difficult questions as to how to cope with the legal position and primary rights of distinct ethnic groups within its political state; how to regard their sociolect-economic structural divergence (e.g. in education, industry, occupation, and income) and cultural differences (e.g. in language, religion, and customs); how to realize their being and evolution (ideology and social norms) and the tendency of ethnic-based movement in the coming; and the strategies and measures the governments should adapt to guide the 
way of inter-ethnic social relation for group equality, social justice, ethnic harmoniousness, social steadiness, and political integrity.

A country with good ethnic social relations will be able to beef up the cohesiveness of its citizens continuously through positive internal unity, minimize administrative and operational reimbursement, raise the efficiency of social and economic groups or institutions, and strengthen its economic power. In a state where politics, economy, and culture shift positive developments, each ethnic group will utilize the benefits brought about by a comfortable economy and by a harmonic society.

On the other hand, a land with poor ethnic social relation will suffer flourishing social dissonance and disintegration origin by internal opposition, followed by an apparent increase in social costs in the forms of money, manpower, and material goods for the maintaining of social order, which in turn will multiple the government's expenditures and citizens' tax burdens. If ethnic disputation turns into open political confrontations or separatist movements, the whole community will be inverted upside down, Accordingly, the government will be quickly diminished the economic foundation and set up will be broken, and the entire ethnic groups will have to suffer the difficulties raise by social riots, economic problems, and political detachment. Then, finally, each ethnic group will become losers. An evident example is witnessed in the transmutation of ethnic relations in previous Yugoslavia. Therefore, ethnic relations have become one of the core problems facing all societies in the twenty-first century in the current world.

This Seminar Report was investigated to promote ethnic group relations in current Ethiopia: A Social-psychological perspective. The background of this study indicates that exposure and interaction in the middle of members of varied ethnic groups help to minimize ethnic conflict-based prejudice and ethnic group tensions through promoting positive and tolerant attitudes and also improves ethnic group relations toward out-groups. Since our country Ethiopia failing in the problems of ethnic-based violence's, working seminars on this current issue is appropriate and the baseline for obeying our responsibilities for the sake of abstaining our country's difficulties through enhancing much optimistic attitude towards out-groups and growing a spirit of trust about outgroups, in turn, advance supportive ethnic group relations.

The reason for selecting seminar topic on Promoting ethnic group Relations in Current Ethiopia: Social Psychological Perspectives is because of the existing problems which are prevailing directly discriminating some ethnic groups being they are only from Amhara ethnics in Oromia before four months and in Somali Region in 2010, Oromo ethnics in Somali Region in 2009 at during the past time, etc. Moreover, there are no more previous studies on promoting ethnic group relations in the Ethiopian context and did not intelligibly show different factors that promote ethnic group relations in various contexts. Therefore, the present article aims to examine the issue of promoting ethnic group relations in current Ethiopia which is best-known as a nation of native national diversity. The paper mainly focuses on looking into factors that promote ethnic group relations. While investigating these factors, the paper also examines the intergroup perspective on the need for increasing intergroup relations. Factors that can improve ethnic group Relations include situations that help to see some of the necessary conditions to improve positive ethnic group contacts and promote positive intergroup relations. Social bond that arises because of reasons like inter-ethnic matrimony and living together is found to have a contribution to positive ethnic relations.

According to the findings of many scholars, in a country where there are multi-ethnic societies, minorities may appear and inter-ethnic tensions, segregation, and even fight may occur among communities [2]. An evaluation of ethnic organization family members in Ethiopia has been defined as "a museum of peoples" (Wagaw, 1999) whose populace is characterized with the aid of using a "complicated sample of ethnic, linguistic and non-secular corporations" (Tronvoll, 2000 , p. 6). There are approximately eighty-three ethnic corporations. For the bulk a part of the cutting-edge records of us, the Amhara become the main ethnic organization. In the past due nineteenth-century alongside, the influential increase that created the prevailing nation of Ethiopia, the Amharic language and the Amhara cultural values ruled the numerous ethnic corporations of southern Ethiopia [3]. The ethnic corporations' family members united into the territory have been believed to be preserved as subjects, and predominantly, their culture, language, and identification have been suppressed (Mengisteab 1997). In 1991, the cutting-edge authorities got here to strength and delivered an ethnicityprimarily based federal system. Consequently, ethnicity has ended up the ideological foundation of the authoritarian's political organization and administration (Abbink 1997).

According to the national policy, Ethiopian cohesion or countrywide identification is primarily based totally on the honor and accommodations of diversity (Van der Beken, 2012). Studies suggest that opposition to the very trouble it become supposed to address, the implementation of ethnic federalism in Ethiopia appears to have created greater issues than it set to solve (Gudina 2007). It is assumed that there are numerous ethnic tensions and conflicts withinside greater than ever earlier than due to ethnic boundaries, ethnic identities, scarce sources, and strength rivalry [4]. Addis Ababa and special Cities are one of the contexts in which ethnic tensions and conflicts occur, and there may bean a growing challenge that they end up the principal fight sector for ethnic battle in Ethiopia. This is so due to the fact an Administration gives contextual in which ethnic corporations are typically cautious to be of same repute irrespective of their backgrounds; they're anticipated to paintings cooperatively to obtain not unusual place goals; cross-organization friendships are viable; and better officers and constitutions legislation, regulations and policies are made-as much as facilitate range and nice ethnic organization family members [5]. In this seminar document, I diagnosed how the examine correctly reaching the authentic objectives of the document, suggest issues that arose withinside the 
direction of the document which couldn't be solved with inside the to be had time. I examine the use of the Contact idea that is influential withinside the examination of enhancing intergroup family members. The essential assumption of touch idea is that after human beings from special backgrounds have the possibility to touch with every different, they locate it greater tough to preserve prejudices towards one another. Contact probably reduces prejudice with the aid of using improving expertise approximately the out-group, lowering tension at an approximately intergroup touch, and growing empathy.

\section{Background}

The word ethnic group members of the family refers to each man or woman interactions regarding individuals from special organizations and the collective conduct of organizations in interplay with different organizations, at both the intra or interorganizational degree. The traditional definition of intergroup members of the family become at first furnished through Sherif [6] who suggested: every time people belonging to at least one institution interact, together or individually, with any other institution or its individuals in phrases in their institution identification, we've got an example of ethnic relation conduct. The social psychology of ethnic group members of the family has a lengthy and wealthy history. Given its unique interest, on the grounds that the start, to phenomena along with racism (Stephan, et al. 1999), prejudice (Mackie, et al. 1996), stereotyping (Deschamps, et al. 1999), discrimination [7] and struggle, it's far as a result comprehensible the way it has become this kind of efficient location of studies and theorizing. Independently of the focal point on societal organizations, along with racial or ethnic organizations, countrywide organizations, spiritual organizations, paintings organizations, or maybe, synthetic organizations, simply to call a few, the focal point at the interactions of humans belonging to organizations and perceiving, considering and appearing in the direction of different those who also are a part of organizations (be them in-organizations or out-organizations) currently units the framework of evaluation in intergroup members of the family. One of the maximum widely recognized definitions of intergroup members of the family become furnished through (Sherif 1962). Intergroup members of the family confer with members of the family among or extra organizations and their respective individuals. Whenever people belonging to at least one institution interact, Theories on intergroup members of the family and contact: together or individually, with any other institution or its individuals in phrases in their institution identifications we've got an example of intergroup conduct.

Although this definition highlights the want to examine people as belonging (or now no longer) to special organizations in a manner to realize their conduct in the direction of different those who belong (or now no longer) to the identical organizations, a long term of studies and advances become important till we got here to such know-how of intergroup members of the family. The first theories reading prejudice (high quality or poor assessment of a set and its individuals (Mackie \& Smith 2003, p. 1), and discrimination (i.e. "poor behaviors directed in the direction of individuals of socially described organizations due to the fact they may be individuals of this institution", (Stephan \& Stephan 1996, p. 35), centered totally on the man or woman degree of evaluation and attempted to explain discriminatory conduct from the attitude of man or woman variations and persona traits. For instance, withinside the Nineteen Thirties and 1940s, the essential causes of prejudice had been primarily based totally on psychodynamic causes of man or woman conduct, which centered on standards along with projection, scapegoating, frustration, and hostility displacement to explain the tendency of (some) people to be prejudiced in the direction of others (Stephan \& Stephan, 1996).

One instance of this interaction among each procedure is the notion in a simply global hypothesis (Lerner, 1980). Its predominant assumption is that sufferers of discrimination or maybe mass violence ought to have performed something horrific and consequently, justify the results delivered upon them. Those self-pleasurable biases function in a manner to push aside societal duty for collective violence and struggle and can affect negatively intergroup members of the family and cooperation. The significance and scope of the trouble entail the numerous forces with-inside the system (country) that synthesize in stimulating the character and mode of selling ethnic members of the family in Ethiopia.

\section{Research questions}

The study is intended to offer a set of contextualizing' patterns of Inter-ethnic relationships through conducting the exploration by portraying the experiences of the communities in psychological perspectives with the general objective of contributing to the understanding, the dilemmas and discourses associated with ethnic diversity. Additionally, a goal is intended to have a positive impact on the socio-political and economic development in contemporary Ethiopia. Specifically, therefore, the study addresses the problem by answering the general research question, what are the main factors that promote and hinder intergroup relations in current Ethiopia?

The study focuses on the following specific questions:

How do ethnic relations can be improved in current Ethiopia?

$>$ How did and/or do ethnic communities remain idiosyncratic? Under what circumstances

What are those factors that thwart mutual integration between the case communities?

\section{Rationale for choosing this topic}

The motive for deciding on seminar subject matter on Promoting ethnic relations in the Current Ethiopian Social Psychological Perspective: due to the fact there are numerous ethnic organizations in Ethiopia. Therefore, running in this subject matter supporting in deal with or lessen such troubles being the distinguished social-mental procedures to constructing social concord keep away from this trouble through selling improved high-quality ethnic members of the family among Oromo and Amhara and converting the character 
of synthetic limitations amongst ethnic organizations so one can sell members of the family amongst them. Social psychology contributes definitely to society through selling social concord. Positive, cooperative relation among individuals of various organizations reduces tension and may generalize past the dealings situation, even as in-institution out-group categorizations may be altered in numerous methods to lower the significance of institution memberships, promotes shared identities, and understand institution variations in a highquality way. Throughout this manuscript, I've got supplied a number of the maximum influential and fertile theories withinside the discipline of intergroup members of the family [8]

I have observed the intent through which we delivered new insights and conceptualizations of intergroup relations, struggle, and emotion advanced over the years, and that has contributed to reinforcing our know-how of intergroup phenomena. At the moment, a great deal of studies is being performed below the subject of intergroup members of the family and emotions. The gift manuscript pursuits to have given a well-known evaluation of the maximum used frameworks inside this discipline, even as additionally contributing to an integration of the ethnic institution touch attitude used withinside the discipline of intergroup members of the family [9].

The motive of this seminar paper had been promoting ethnic members of the family and exploring elements that facilitate and obstruct high-quality intergroup members of the family and inspecting efforts made to enhance high-quality intergroup members of the family withinside modern-day Ethiopia. The result identifies that multi-group club which ends up from the wedding among special ethnic groups and primarily based totally on their belongingness contributed to developing possibilities for intergroup relations and growing high-quality intergroup members of the family amongst ethnic organizations. The end result additionally offers essential insights approximately elements that obstruct highquality intergroup members of the family amongst ethnic organizations members of the family [10].

\section{Materials and methods}

This study hired a qualitative examination approach to assist the in-depth investigation of promoting ethnic group relations in current Ethiopia from respondents' point of view and in a bestowed societal as well as official context. According to Ethiopian Central Statistical Agency (CSA, 2013) [11], showed that some ethnic groups in Ethiopia are: $34.6 \%$ Oromo, 27.1\%Amhara, 6.1\%Somali, 6.1\%Tigrayan, 4\%Sidama, $2.5 \%$ Gurage, $2.3 \%$ Welayta, $1.7 \%$ Hadiya, etc. While collecting the necessary data through interview were successful and focus group discussion were not conducive inappropriate because of the existence of covid-19. Even though, we try to reduce the numbers of participants to 6 to prevent covid-19 and then, make focus group discussion by making as they were keeping their distances and wearing their masks. Participants 15 Christians, and 15 Muslims Ethiopian adults (12 female and 18 male), between 18 and 24 years old, voluntarily consenting to take part in the study. The study was conducted in Eastern Hararghe, one of the Zone in the Oromian Region in Ethiopia especially, at Jarso Woreda. It is located in Eastern Oromia and located around Harari Region, Somali, and Dire Dawa. It became a zone around 1987 as a result of the coming EPDRF. Jarso Woreda has above 100,000 populations according to Ethiopian Central Statics Agency, 2006. The data were collected between September and January 2013. The majority of the data were collected from thirty 30 participants from 6 various ethnic backgrounds (Amhara, Oromo, Geedio, Gumuuz, Somali, Tigre, and Mixed ethnicity)

In-depth interviews have been performed with the ten employers, 10 residents, and 10 youths. Qualitative semi-based interview timetable turned into used as it permits specializing in important troubles and incorporating troubles which can also additionally rise at some stage in the interview. Among the ten youths, Interviews with 30 college students have been performed in Afaan Oromo and Amharic due to the fact they favored each Amharic and Afaan Oromo to sound their ideas. Focus institution dialogue turned into additionally performed with 6 youths to gain institution insights and understandings on promoting ethnic institution members of the family in Ethiopia. Half of the FGD individuals additionally participated withinside the interview. To grow individuals' consolation at some stage in institution discussions (Morgan, 1998), they have been grouped primarily based totally on ethnic heterogeneity. For this purpose, individuals in every FGD have been decided on from six(6) ethnic historical past, and that they knew every different earlier than coming to take part withinside the group dialogue. To acquire this, functional heterogeneity and snowball sampling strategies have been used. The first purposefully decided on youths nominates some other youths from ethnic agencies whom he/she is snug with to talk about the problem beneath-neath observe. This choice procedure persisted till achieving an inexpensive quantity of individuals. An overall of 4 FGDs with 6th unique ethnic agencies has been performed with among 2 and four human beings every. The choice of ethnic agencies turned into in particular primarily based totally on the modern-day ethnic majority-minority dichotomy, and data received from preceding researches and through interview approximately agencies which can be regularly worried in ethnic conflict. Based on those criteria, the Amhara, Gambella, Oromo, Tigre, Somali, and Guraghe, ethnic agencies have been decided on. The discussions with Amhara, Oromo, and Tigre youths have been in Amharic and the dialogue with Oromo turned into in Afaan Oromo. The generated facts have been analyzed through the usage of a thematic method. The facts evaluation manner accompanied translating, transcribing, coding, figuring out the recurrent troubles that emerged from the facts, and in the end, studying them thematically. To hold confidentiality, in direct quotations individuals have been addressed the usage of abbreviations accompanied through numbers. The trustworthiness of the observation turned into in particular greater through triangulation throughout facts re assets and methods. In the approaching sections, first I discuss, as discovered through my observation, the elements that facilitate and hinder high-quality intergroup members of the family in a neighborhood context. 


\section{Conceptual and literature review}

Overview of Inter-ethnic integration in Ethiopia: The root, way of occurrence, and modes of integration among ethnic or linguistic communities in the evolution of historical processes in the traditional Ethiopian polities had been a varied voyage that could realize a bit more exactly in its context particularity. This part is, so, an effort to locate our challenging eth-no religious past in context so that one can imagine the essence of his/her identity of sense of Ethiopia from the stimulating, occasionally, awful history of our diverseness that device our thoughts by penchant prejudices of the 'elitist' political affairs. Contemporary Ethiopia is a land made up of many-sided ethnic and linguistic threads comprising (Pankhrust 1990) the Semitic, largely in the north with pockets in the south; the Omotic in the southwest; Cushitic largely in the south with pouch in the north and the Nilo-Saharan in the far west, close the Sudan border. Instead, it resulted from the in-migration, differentiation, and combination of super-language families at the first glance of Ethiopian history.

Intermarriage between members of different ethnic or religious communities is common in Ethiopia, principally in areas where a multitude exists. Possibly, ethnic hybridity of diversity through familial relation has theoretical and practical importance for the indication of mutual permissiveness that transcends the existing primordial ethnic/ linguistic differentiation. Consequently, (Hetzron, cited in Sheriff 1985) indicates that the Semitic group had intermingled with the endemic Cushitic citizenry to form the ancient Ethio-Semitic language A New frontier in the inter-ethnic 30speakers. As a consequence of inter matrimony. Trimingham (1952) noted that the coalition of diverse communities into a culturally homogeneous people, and, yet, developed indigenous civilization with little alien influence other than the Sabean civilization. This amazing matrimony of different people in Ethiopia has further supported within (Pankhrust 1990) the history of population movements in various forms from across every direction. Hence, historical movements of people have made possible the social phenomena of bilingualism, and, indeed, multilingualism that sufficiently reveals the patterns early of inter-ethnic interaction perhaps based on mutual assimilation and integration.

\section{Theoretical background}

Theoretical Perspectives on ethnic members of the family, as a topic matter, were subjected below numerous/numerous theoretical expositions. It must be mentioned that numerous theories have tried to explain intergroup members of the family as a topic matter. However, for clean know-how of the causes, dynamics, and complexities of enhancing ethnic members of the family in Ethiopia, it's far consequently to study a number of the difficult theories on enhancing intergroup members of the family will applicable. The Intergroup touch concept (Brown \& Hewstone, et al. 2005), which has its starting place in Gordon Allport's (1954) touch hypothesis, holds that folks who interact in intergroup touch (the residences of which can be defined below) are possibly to be much less prejudiced closer to out-institution individuals than are individuals who do now no longer have such touch experiences. Intergroup touch can take many forms, and we first speak the maximum usually studied type, that is, direct, face-to-face touch, and deal with while and the way it's far powerful; we then define findings from numerous different kinds of touch on the stop of this section [8].

Although this definition highlights the want to examine people as belonging (or now no longer) to special organizations in a manner to realize their conduct in the direction of different those who belong (or now no longer) to the identical organizations, a long term of studies and advances become important till we got here to such know-how of intergroup members of the family. The first theories reading prejudice (high-quality or poor assessment of a set and its individuals (Mackie \& Smith, 2003, p. 1), and discrimination (i.e. "poor behaviors directed in the direction of individuals of socially described organizations due to the fact they may be individuals of this institution", (Stephan \& Stephan 1996, p. 35), centered totally on the man or woman degree of evaluation and attempted to explain discriminatory conduct from the attitude of man or woman variations and persona traits. For instance, withinside the Nineteen Thirties and 1940s, the essential causes of prejudice had been primarily based totally on psychodynamic causes of man or woman conduct, which centered on standards along with projection, scapegoating, frustration, and hostility displacement to explain the tendency of (some) people to be prejudiced in the direction of others (Stephan \& Stephan, 1996).

The predominant assumption of a maximum of those theories becomes that, for humans to act in this kind of poor and condemning way there needed to be something incorrect with them as persons. Additionally, the broadly unfold prevalence of prejudice and discrimination couldn't be defined through people's non-public dispositions to come to be suggestive of evil. Consequently, as Pennekamp (2008) thoroughly declares, "given the truth that prejudice and discrimination particularly get up while a set's identification is salient, there must be something approximately organizations that causes (big elements of) its individuals to interact in struggle" (p. 7)

To summarize given the defaults of this method and the shortage of ability explanatory energy for positive societal phenomena, new procedures and theories had been advanced, to explain intergroup members of the family marked through prejudice, discrimination, or maybe struggle. Consequently, because of the start of the Sixties and 1970s, sociocultural causes won relevance withinside the examination of intergroup members of the family. Still, it's far essential to notice that man or woman degree and sociocultural degree causes aren't at the same time exclusive. We must undergo in thoughts that man or woman and societal styles of prejudice might also additionally give a boost to every different and move hand in hand while people locate justifications for the lifestyles of prejudice and discrimination (Stephan \& Stephan 1996). One instance of this interaction among each procedure is the notion in a simply global hypothesis (Lerner 1980). Its predominant assumption is that sufferers of discrimination or maybe mass violence ought to have performed something horrific and consequently, justify the results delivered upon them. Those 
self-pleasurable biases function in a manner to push aside societal duty for collective violence and struggle and can affect negatively intergroup members of the family and cooperation.

We have a look at the use of the Contact concept that is influential withinside have a look at enhancing intergroup relations. The essential assumption of the touch concept is that once human beings from one-of-a-kind backgrounds have the possibility to relate with every different, they locate it greater relations to maintain prejudices towards one another. Contact doubtlessly reduces prejudice through improving information approximately the out-corporations, lowering tension approximately intergroup relations, and growing empathy.

Allport's Intergroup Contact Hypothesis Allport (1954) held that high-quality results of intergroup touch arise most effective in conditions marked through 4 key conditions: identical organization fame withinside the state of affairs; not unusual place dreams; intergroup cooperation; and the aid of authorities, law, or custom. (1) Equal Status: Allport burdened identical organization fame withinside the state of affairs. Most studies help this contention, although "identical fame" is tough to outline and has been utilized in one-of-akind ways (Cagle 1973, Riordan 1978). Each corporation must assume and understand identical fame withinside the state of affairs (Cohen \& Lotan 1995, Cohen 1982, Riordan \& Ruggiero 1980, Robinson \& Preston 1976). Some writers emphasize identical organization fame getting into the state of affairs (Brewer \& Kramer 1985). Thus, Jackman \& Crane (1986) display poor results from touch with outgroup participants of decreased fame. Yet Patchen (1982), in studies on racially blended excessive faculties, discovered this to be much less vital than identical fame withinside the state of affairs. The meta-analytic consequences of Mullen, et al. (1992) make clear those disparities. They stated that ingroup bias extended with relative fame in laboratory corporations however reduced in subject studies with actual corporations. (2) Common Goals: Prejudice discount through relations calls for an active, goalorientated attempt. Athletic groups supply a high example (Chu \& Griffey 1985, Miracle 1981, Patchen 1982). In striving to win, interracial groups want every different to acquire their goal. Goal attainment, which includes a triumphing season, furthers this technique for private use most effectively. (3) Intergroup Cooperation: Attainment of not unusual place dreams need to be an interdependent attempt without intergroup competition (Bettencourt et al 1992). Sherif [6] validated this precept vividly in his Robbers' Cave subject have a look at. Intergroup cooperation in faculties offers the most powerful proof (Brewer \& Miller 1984, Desforges, et al. 1991, Johnson, et al. 1984, Schofield 1989, Slavin 1983, Slavin \& Madden 1979). Drawing on this thinking, Aronson's jigsaw study room approach systems school rooms so that scholars attempt cooperatively for not unusual place dreams (Aronson \& Patnoe 1997). This approach has brought about high-quality consequences for numerous children: Australians (Walker \& Crogan 1997), Germans (Eppler \& Huber 1990), Japanese (Araragi 1983), and Mexican Americans (Aronson \& Gonzalez 1988). (4) Support Of Authorities, Law, Or Custom: The very last situation issues the touch's auspices. With express social sanction, intergroup touch is greater comfortably ordinary and has greater high- quality results. Authority aid establishes norms of acceptance. Field studies underscores its significance in the military (Landis, et al. 1984), business (Morrison \& Herlihy 1992), and religious (Parker 1968) institutions.

I do now no longer argue that intergroup touch is an answer as a way to set proper all problems. However, the great proof is that touch does now no longer commonly pass downhill intergroup relations, and its standard effect, throughout loads of studies, is to enhance them [12]. Intergroup touch studies have evolved to such a quantity that we've got totally clean expertise of while and the way it works. We know, for example, that to be maximally powerful, touch results need to generalize past the person's out-organization touch companion and that this calls for organization salience and perceived typicality of the touch companion. Contact results additionally generalize from one touch state of affairs to another, and throughout different out-corporations, as a consequence having farachieving high-quality multiplier results. We have proven how diverse functions of the intergroup context play a pivotal moderating function in selling the effectiveness of touch, along with organization fame, person tiers of prejudice, previous tiers of touch, and intergroup ideologies. A wealth of studies has additionally unearthed quite a number of mediators through which touch exerts its results, along with intergroup tension, empathy, information, and perceived threats. We have labored seminar file that has moved past face-to-face touch and taken into consideration the effectiveness of different sorts of touch, which includes touch through the internet, social touch, prolonged touch, and imagined touch, every of which may also have a precise fee in selling peace and reconciliation in fantastically fraught intergroup contexts. Thus, the big literature at the moderators, mediators, and sorts of touch offer sensible steering on the way to maximum successfully hire intergroup touch [9]. In thinking about the function of touch in violent struggle resolution, we centered our interest on struggle zones, in Ethiopia, and confirmed how touch has been powerful at growing readiness to reconcile and sell emotions of trust, forgiveness, and empathy. We additionally took into consideration the small frame of studies wherein touch has been used as a struggle prevention approach even as being cautious to emphasize that, given the dynamic nature of intergroup relations, it's far at instances tough to differentiate sincerely among struggle discount, resolution, and prevention.

\section{Factors promoting inter-group relations}

In this observation, elements that facilitate intergroup members of the family consist of conditions that contribute to fulfilling a number of the important situations to decorate powerful high-quality intergroup contacts and thereby enhance high-quality intergroup members of the family. Social bond that arises due to motives like intergroup marriage and residing collectively is located to have a contribution to highquality intergroup members of the family.

\section{Multi-group membership marriage}

Throughout ethnic traces may be very not unusual place a few of the Ethiopian society, and it's far one of the functions 
that cement Ethiopia as a multinational nation through making ethnicity much less relevant. The marriage among unique ethnic agencies has created a big quantity of various ethnic populations. This has ended in a combined ethnic youths agencies withinside the country. Participant youths from combined ethnic historical past declare club in multiple ethnic institutions. Following responses from youths make this clear: It is hard for me to pick out myself with regards to a specific ethnic institution. My father is Oromo and my mom is Amhara. I don't have a unique association with both of those ethnic agencies. I simply experience that I am each Amhara and Oromo. ...It doesn't count what ethnic institution I belong to, due to the fact we're all Ethiopian. (YTH62) I don't need to and additionally cannot say I belong simplest to this ethnic institution due to the fact I am a combined ethnic person. I grew up withinside the Amhara lifestyle and my pals took into consideration of me Amhara, however, the reality is I even have Amhara, Sidama, and Wolayita ethnic historical past. I can't erase this reality. So, I commonly opt to mention that I am an Ethiopian without connecting myself to at least one ethnic institution. (YTH65) These excerpts suggest that further to claiming multi-institution club, combined ethnic identification facilitated the notion and improvement of not unusual place identification which makes youths Such a not unusual place in-institution identification has helped Youths to emphasize similarities as opposed to differences and to lessen intergroup bias along with prejudice, stereotype, and discrimination through growing an extra inclusive institution [13]. This in flip appears to have helped them to set up a highquality intergroup cooperation (Allport, 1954) and which might be important situations to be met to decorate high-quality intergroup members of the family [12]. Following responses from college students make this clear:

It is hard for me to become aware of myself with regard to a selected ethnic organization. My father is Oromo and my mom is Amhara. I don't have a unique association with both of those ethnic companies. I simply sense that I am each Amhara and Oromo. ...It doesn't count number what ethnic organization I belong to, due to the fact we're all Ethiopian. (YTH64).

I don't need to and additionally cannot say I belong best to this ethnic organization due to the fact I am a combined ethnic person. I grew up withinside the Amhara way of life and my pals took into consideration me Amhara, however, the reality is I actually have Amhara, Sidama, and Wolayita ethnic backgrounds. I can't erase this reality. So, I generally opt to mention that I am an Ethiopian without connecting myself to 1 ethnic organization. (YTH65)

\section{Factors hindering intergroup relations}

Factors that obstruct intergroup members of the family consist of conditions or problems that during one manner or any other have poor effects on achieving one of the important situations to beautify powerful fine intergroup relations and thereby enhance fine intergroup members of the family. Government system, coverage, and method which might be associated with ethnic federalism, political membership, languages, and scholar placement are discovered to have a poor impact on the intergroup members of the family.

\section{Language and ethnicity based friendship}

Youths stay in societies, socialize and attend with citizens from distinctive ethnic backgrounds. This gives them many possibilities for growing cross-ethnic friendships and fine intergroup members of the family. However, withinside the FGDs, youths prominent the developing tendency of ethnicity-primarily based totally friendship. There are motives for the elevated ethnic choice in near friendship selection. Communication trouble influences contacts among distinctive companies that are the spine of Allport's intergroup touch theory. The significance of a not unusual place language in friendship is unarguable, due to the fact it's far hard to set up a friendship if humans aren't capable of speech and recognize every difference due to the language barrier. For example, Amharic is spoken to me through a maximum of Ethiopians:

I do now no longer communicate Amharic. So, I use my language [Oromic and Amharic language] to speak with youths from my ethnic organization, and English to speak with different college students. As you know, maximum college students use Amharic, now no longer English, to speak with every different. So, it's far a massive project for us to speak, speak and socialize with maximum college students withinside the college and additionally with humans out of doors their companies (YTH62).

\section{Prejudice, stereotypes and ethnocentrism}

In the FGDs, youths prominent that their preconceived judgments approximately out-companies now and again negatively prompted the connection among them and outorganization contributors. Youths' prejudicial and stereotypical attitudes are frequently meditated at some stage in hectic debates among contributors of various companies. Though there are numerous stereotypes and prejudices referred to through youths, to illustrate their effect on intergroup members of the family (YTH63). Ethnocentrism is a well-known phenomenon that isn't restrained to positive companies or cultures (Lewis, 1985). This means that all people are ethnocentric to a few degrees (Triandis, 1994). Youths said that after they speak about problems associated with ethnicity and religion, ethnic majority college students generally tend to assess others way of life in phrases in their personal way of life. This is due to the fact ethnic companies which might be culturally, numerically, and politically dominant generally tend to accept as true with and display they're higher than others. The study additionally shows that "attitudinally, ethnocentric organizations see themselves as sturdy and superior, at the same time as viewing out-companies as inferior and weak. Because of this, generally, contributors of ethnic companies who're taken into consideration are not as good as others lower or keep away from discussing ethnic problems with out-organization contributors, and this in flip decreases intergroup touch and thereby influences fine intergroup members of the family on City. Among a few ethnic companies, an ethnocentric mindset and conduct now and again even turns into one of the most important motives for interethnic conflict. 


\section{Equal group status within the situation and cross-group friendship}

Are a number of principle situations that want to be met to facilitate fine intergroup touch and intergroup members of the family [12]. Yet, youths' ethnocentric, stereotypical and prejudicial mindset and conduct project the identical popularity of various ethnic companies and make crossorganization friendship hard, and this typically impedes the ethnic organization relation amongst youths.

\section{Results and discussions}

In this section, a strive is made to reply to the important thing seminar questions raised in advance primarily based totally at the outcomes of interviews and institution discussions. Following that, the extent of ethnic institution family members as interviewed objects that qualitative responses received from the outcomes of respondents' ethnic businesses mindset on the premise of the IEA subscale. The objects determine the mindset of the respondents in the direction of the tradition, music, and language, which together degree their mindset in the direction of ethnic out-businesses. To discover whether or not or now no longer ethnic heritage subjects in shaping attitudes in the direction of contributors of ethnocultural outbusinesses, become computed to take a look at similarities feature of ethnic heritage. To that effect, institution variations have been tested if indeed, ethnic identification determines students' mindset in the direction of (a) celebrating their very own ethnocultural identification (b) mindset in the direction of different ethnic and spiritual businesses; (c) experience of shared countrywide identification (d) feeling of an experience of duty to serve their us of a and protect on the time while there may be outside hazarded for its security (Patriotism); and (e) their volume of cross-institution cohesiveness. It is argued that the effect of ethnic primarily based Federalism that denied the rights of numerous ethnic group family members in realistic place to tall their language and exercises their tradition (for example, Bulcha, et al., 2008) extensively undermined their experience of satisfaction and collective self-efficacy. In effect, the non-dominant ethnic group have been compelled to beyond grievances their history, give up their tradition and language [14]. As depicted in(YTH62), the look at as compared six ethnic businesses with recognize to the diploma to which youths belonging to Amhara, Oromo, Tigray, Somali, Gambela, and Southern and NNP range in phrases of taking satisfaction of their ethnocultural identification. The opportunity signs used to evaluate selling elements and impediments elements in the direction of ethnic groups family members have been as follows: taking element in cultural activities or taking place vacations with their very own ethnic institution and social bond that arises due to motives like intergroup marriage and residing collectively is discovered to have a contribution to high-quality intergroup family members [15-19].

On the opposite hand, the findings typically display that a majority of the scholars held a high-quality mindset in the direction of fellow Ethiopians belonging to different ethnic businesses and are probably to select buddies from ethnocultural or spiritual out-group. Though those findings may be regarded as correct warning signs of the prevailing intergroup family members, variations nevertheless exist in some of the studied ethnocultural businesses in phrases of the diploma of orientation to one's very own ethnic identification.

To test the effectiveness of the manipulation, we performed on individuals' responses to the objects concerning their intentional attention in the course of the interviewing and FGD. As expected, the family members become significant. Confirming the helpfulness of the operation, individuals withinside the relational make-accept as true with touch situation mentioned having targeted greater on relational individualities of the met man or woman than on intergroup variations, even as individuals withinside the intergroup myth touch situation mentioned having targeted greater on intergroup characteristics) than on relational ones. Between situations relationships similarly indicated that the of the social object become better for individuals who believed touch on the inter non-public stage than for people who believed it on the intergroup stage. Conversely, the outcomes of the intergroup object become better for individuals assigned to the intergroup believed touch situation than for the ones withinside the interpersonal situation. We additionally analyzed responses to the positivity object to test whether or not individuals imagined an undoubtedly toned scenario, and whether or not the sort of training encouraged perceived positivity. Results confirmed that for each the interpersonal and the ethnic institution situations outcomes have been meaningfully better than the intermediate of the balance respectively. Most importantly, those outcomes have been now no longer distinct from every different, indicating that the extent of institution relation understood withinside the order did now no longer affected the positivity of the myth relation.

\section{Conclusion}

In contradiction of the heritage of the ethnic-primarily based federal system, the prevailing seminar studied selling ethnic family members in modern-day Ethiopia. Furthermore, the exam attempted to perceive the elements which impose on ethnic organization family members. As it grew to become out, the effects did now no longer offer empirical assist to promote entitlement that reputation of ethnic organization relation withinside the public sphere jeopardizes intergroup family members. Nor did it display a sample of intergroup tensions.

The number one focuses of this examination is on promoting ethnic family members and exploring elements that facilitate and hinder intergroup family members and having a look at determinations made to enhance ethnic group family members in modern-day Ethiopia. Since Ethiopia failed in intergroup conflicts operating in this, problems decreased such through improving extra high-quality mindset in the direction of outcompanies and develop a sense of belief with regards to outcompanies in flip promotes high-quality ethnic organization family members. We do now no longer argue that intergroup relations are an answer on the way to set proper all problems. However, the quality proof is that relations do now no longer commonly cross downhill ethnic group family members, and its average impact, throughout masses of research, is to enhance 
them. Ethnic group relations research has advanced to such a volume that we have a completely clean information of while and the way it works. We know, for example, that to be able to be maximally powerful, touch results have to generalize past the person's out-organization touch companion and that this calls for organization salience and perceived typicality of the touch companion. A touch concept additionally simplifies from one touch scenario to another, and throughout different outcompanies, for that reason having far-attaining high-quality multiplier results. We have proven how numerous functions of the ethnic organization context play a pivotal controlling function in figuring out the effectiveness of touch, which includes organization status, person tiers of prejudice, earlier tiers of touch, and ethnic organization perspective. A wealth of research has additionally unearthed quite a number of mediators with the aid of using which touch exerts its results, which includes organization anxiety, empathy, knowledge, and perceived threats. In thinking about the function of relations in violent war resolution, we centered our interest on ethnic relation, confirmed how relations have been powerful at growing readiness to reconcile and sell emotions of belief, forgiveness, and empathy. We additionally took into consideration the small frame of examination wherein touch has been used as a war prevention method whilst being cautious to emphasize that, given the dynamic nature of ethnic organization family members, it's far at instances tough to differentiate truly among war discount, resolution, and prevention.

Finally, I explored a few feasible accidental effects of relations, including ignoring significant organization variations and structural ethnic organization disparities and discouraging organization participants from accomplishing collective motion geared toward social change. While those are actual risks that we have to renowned and shield against, I argue that employer and intergroup relations want now no longer be collectively different and that a nuanced and touchy use of intergroup relations, primarily based totally at the big frame of realistic examine, can enhance ethnic organization family members whilst stabilizing collective companies. Ethnics relations have to, however, as noted, be a part of an extra important technique that consists of adjustments in coverage that have an impact on the goal and long-status foundation of ethnic group war. As a whole, ethnic organization relation presents extensive precis of examine on arguably the maximum influential concept of prejudice discount in social psychology. Since its beginning, the ethnic organization relations concept has extended into new varieties of touch (e.g., imagined touch and prolonged touch), and advances withinside the floor permit for deeper information of the mechanisms in the back of ethnic organization touch.

There are many fruitful regions of destiny examined to promote higher information and promoting ethnic organization contacts. For destiny directions, some topics emerged. First, to higher apprehend the scope of ethnic group relations, extra research desires to have a look at the results of each highquality and bad relations, as examination shows that bad ethnic group touch is a more potent predictor of attitudes than high-quality relations. Second, extra examination on intergroup touch ought to increase past conventional measures of self-stated attitudes to evaluate behavioral effects of touch each through self-document and unobtrusive measures (e.g., nonverbal behavior). Third, extra examine ought to discover how intergroup relations influences minority or deprived people. The majority of the touch literature specializes in how ethnic organization touch impacts results amongst majority (advantaged) people, with little research analyzing how minority (deprived) people are affected. As such, destiny research ought to have a look at how ethnic organization touch impacts attitudes and behaviors amongst majority ethnic and minority ethnic. Fourth, more recognition on programs of touch concept examine to actual-international contexts is important to make sure the blessings of ethnic organization touch being implemented to conditions and contexts wherein they may be useful. For example, intergroup touch may be facilitated in several approaches outdoor of direct touch (e.g., prolonged, vicarious, imagined), which offer a few of the identical prejudice-decreasing blessings as direct relations.

As a few people lack touch possibilities, facilitating prolonged, vicarious, and/or imagined relations is important for decreasing prejudice and enhancing out-group attitudes. Creating or encouraging high-quality intergroup touch possibilities online may be certainly considered one among many approaches to enhance intergroup family members. As such, the findings offered in the intergroup touch concept offer many fruitful streets for the ones interested by ethnic family members. The theory is the maximum complete and ahead questioning evaluation of ethnic organization touch concept to date.

\section{Implications}

Social psychology contributes undoubtedly to society via promoting social harmony, Positive, cooperative relationships among contributors of various companies reduces tension and may generalize the significance of organization memberships, improve shared identities, and tremendously apprehend organization variations. Our hints any upgrades that might be made withinside the destiny to enhance the paintings through the use of comparisons, evaluations, and critiques on the way to problematic the fast comings and supply course for correction. Intergroup family members mean, therefore, the lifestyles of jointly one-of-a-kind group which might be inconsistent interplay with each other. These joint one-of-akind group because of the mode in their social bond generally showcase we 'mindset in the direction of contributors in their mutual organization whilst showing the they' mind-set to the opposite contributors of the out-group.

Inter group family members mean therefore, the lifestyles of jointly one-of-a-kind group which might be in consistent interplay with each other. These jointly one-of-a-kind group because of the mode in their social bond generally showcase the 'we 'mind-set (e.g.) Amhara and Oromo, Oromo and Tigre, and Amhara and Tigre in the direction of contributors in their mutual organization whilst showing the 'they' mindset to the opposite contributors of the out-organization. The supportive concept in some others have a look at of promoting ethnic group 
family members how human beings in a single organization (the 'in-group') consider and act closer to contributors of some other organization (the 'out-organization') social psychologists.

Emphasized ethnic group relations in local area by relating to Eastern Hararghe Zone of Amahara, Oromo, Somali, and other ethnics where living, cultures particularly, in Jarso Woreda is on the individual, which in its worst forms of ethnic relations can foster selfishness or indifference to others. However, promoting a sense of relations goes beyond a single ethnic group rather to focus on interdependence and relationships. From a contact psychological perspective, improving ethnic groups' relation ultimately depend on each others. Even though, in our local were not a sense of mutually practicing is not fully advantageous because of the existence of Oromo ethnic superiority practicing oppressing on the other small ethnic groups in terms of ethnocentrism. For Example, Sense of large ethnic group and minority separation. It can be strengthened by ignoring the sense of attacking ethnic diversity within a community by the name of indigenous ethnic group superiority as well as inferiority, cannot prevail the solution especially, for neighbors' risky, withdrawal from the community may be transferring for the community. Therefore, such negative attitudes must be practiced without a sense of in-group or out-group of Oromo or Oromo and it should be balanced through doing accepting differences by promoting positive perception towards others, and acknowledged interdependence with others, a willingness to maintain this interdependence by giving equalities for minority groups those who perceived as minorities by the superior one.

Application of ethnic group Contact As articulated through touch interventions the goal at struggle decision ought to encompass positive vital characteristics. First of all, they ought to, in a way as possible, encompass situations for top-quality touch, together with the same status, cooperative interactions in the direction of a not unusual place goal, and institutional support. They ought to contain individuals who're sufficiently traditional in their organization and get in touch with them ought to be of a customized nature, permitting individuals to get to recognize each other as individuals. For lasting results, touch ought to be repeated and prolonged. A clean hyperlink ought to be made among the interplay companion and his or her out-organization so that generalization of the tremendous touch impact can unfold to the out-organization as a whole, furnished that such organization salience does now no longer show to be threatening for individuals. Arguments that the faculty context gives an in particular secure and precious putting inside which to perform mainly designed intergroup touch packages, because, at the least in desegregated systems, colleges quite simply permit for the introduction of diverse situations of top-quality touch. However, as we've seen, there have additionally been examples of packages out of doors in the faculty context, in mainly created camps over the airwaves or related to cautiously facilitated tribunals which display that interventions want now no longer be constrained to colleges. As lengthy, because the studies putting gives the possibility for the vital elements defined above to be met, and furnished that a few different vital functions of the setup are attended to, together with having a balanced majority-minority ratio touch interventions may be a hit throughout a number settings, making them an extremely effective method to remedy struggle.

\section{References}

1. Eshete A (2003) Ethnic federalism: new frontiers in Ethiopian politics. In the first national conference on Federalism, Conflict and peace Building. Ministry of federal affairs and German technical cooperation. Addis Ababa.

2. Baharuddin SA (2008) Many ethnicities, many cultures, one nation: The Malaysian experience. Institut Kajian Etnik (Universiti Kebangsaan Malaysia, 2008). Link: https://bit.ly/3Dyp0w0

3. Carollee LH, Brandt C (2007) Merrill-Palmer Quarterly 3.

4. Adriana-Elena TF, Moraru A, Stoica M, Gorea B, Solovastru A (2011) Procedia -Social and Behavioral Sciences 15: 3263-3267.

5. Adamu AY (2013) Intergroup Relations Among Ethnically Diverse University Students in Ethiopia Journal of Education and Research 3: 77-95. Link: https://bit.ly/3dsgv4a

6. Sherif M (1966) In Common Predicament: The Social Psychology of Intergroup Conflict. Boston: Houghton-Mifflin. Link: https://bit.ly/3GqB2IW

7. Eller D, Abrams D (2003) "Gringos" in Mexico: Cross-sectional and longitudinal effects of language school-promoted contact on intergroup bias. Group Processes \& Intergroup Relations 6: 55-75. Link: https://bit.ly/3GgBS40

8. Al Ramiah A, Hewstone M (2013) Intergroup contact as a tool for reducing, resolving, and preventing intergroup conflict: Evidence, limitations, and potential. Am Psychol 68: 527-542. Link: https://bit.ly/3lu9e1W

9. Figueiredo A, Valentim JP, Doosje B (2014) Theories on intergroup relations and emotions: A theoretical overview. Psychologica 57. Link: https://bit.ly/3y4xP8N

10. Dovidio JF, Kawakami K, Gaertner SL (2002) Implicit and Explicit Prejudice and Interracial Interaction. Journal of Personality and Social Psychology 82: 62-68. Link: https://bit.ly/3pzYTJf

11. CSA (2013) Ethiopia Time Use Survey. Centeral Statistical Agency 1-92. Link: https://bit.ly/3EMKT52

12. Pettigrew TF (1998) Intergroup contact theory. Annual Review Psychology 49 65-85. Link: https://bit.ly/3IGVFm0

13. Molina LE, Wittig MA (2006) Relative Importance of Contact Conditions in Explaining Prejudice Reduction in a Classroom Context: Separate and Equal? Journal of Social Issues 62: 489-509. Link: https://bit.ly/3ox08JV

14. Semela T (2012) Intergroup Relations among the Ethiopian Youth: Effects of Ethnicity, Language, and Religious Background. Journal of Developing Societies 28: 323-354. Link: https://bit.ly/304FSWy

15. Pettigrew TF (1997) Generalized Intergroup Contact Effects on Prejudice. Personality and Social Psychology Bulletin 23: 173-185. Link: https://bit.ly/3IrSjNw

16. Levin S, Van Lar C, Foote W (2006) Ethnic Segregation and Perceived Discrimination in College: Mutual Influences and Effects on Social and Academic Life. Journal of Applied Social Psychology 36: 1471-1501. Link: https://bit.ly/3pzWXQR

17. Nier SL, Gaertner JF, Dovidio BS, Banker MW, Christine CR, et al. (2001) Changing interracial evaluations and behavior: The effects of a common group identity." Group Processes \& Intergroup Relations 4: 299-316. Link: https://bit.ly/3rNcvni 
18. Paolini S, Hewstone M, Voci A, Harwood J, Cairns E (2006) Intergroup contact and the promotion of intergroup harmony: The influence of intergroup emotions. In R. Brown \& D. Capozza (Eds.), Social identities: Motivational, emotional and cultural influences. Hove, England: Psychology Press 209-238. Link: https://bit.ly/3dy2hyx
19. Smith TB, Sylva L (2011) Ethnic Identity and Personal Well-Being of People of Color: A Meta-Analysis. Journal of Counseling Psychology 58: 42-60. Link: https://bit.ly/3rM1vGx

\section{Discover a bigger Impact and Visibility of your article publication with}

\section{Peertechz Publications}

\section{Highlights}

* Signatory publisher of ORCID

* Signatory Publisher of DORA (San Francisco Declaration on Research Assessment)

* Articles archived in worlds' renowned service providers such as Portico, CNKI, AGRIS, TDNet, Base (Bielefeld University Library), CrossRef, Scilit, J-Gate etc.

* Journals indexed in ICMJE, SHERPA/ROMEO, Google Scholar etc.

* OAI-PMH (Open Archives Initiative Protocol for Metadata Harvesting)

* Dedicated Editorial Board for every journal

* Accurate and rapid peer-review process

* Increased citations of published articles through promotions

- Reduced timeline for article publication

Submit your articles and experience a new surge in publication services (https://www.peertechz.com/submission). 